\title{
Regressão espontânea de Lesōes maculosas na Blastomicose de Jorge Lôbo
}

\author{
Paulo de Almeida Machado \\ Instituto Nacional de Pesquisas \\ da Amazônia
}

\begin{abstract}
SINOPSE
O estudo da blastomicose de Jorge Lôbo entre os indios Caiabi, iniciado pelo Autor em 1962, propiciou observações sobre a evoluçäo das lesōes dermatológicas, registrando-se, em alguns casos, a regressảo espontânea das lesões maculosas.
\end{abstract}

\section{INTRODUÇÃO}

O primeiro registro da blastomicose de Jorge Lôbo entre índios brasileiros, deve-se a Pereira Filho (1957) que a observou, em dois indios do Alto Xingu, "lesỗes atróficas, aparasitadas, com sensibilidade conservada e aspecto clínico que lembra placas de lepra tuberculóide". As estampas VI, VII e VIII, do trabalho de Pereira Filho ilustram o tipo de lesão que foi mais tarde denominada maculosa pelo autor.

O trabalho de Pereira Filho não esclarece a que tribo pertenciam aqueles índios.

Em 1966, P. A. Machado comunicava ao XVI Congresso Brasileiro de Higiene, Curitiba, a primeira observação da ocorrência da Blastomicose de Jorge Lôbo na aldeia dos índios Caiabi, no rio Tatuí, fora do Parque do Xingu. Foram observados e descritos 11 casos, distinguindo-se lesões queloidiformes, lesōes simulando máculas de hanseniase tuberculóide reacional, lesões nodulares, lesões gomosas e um único caso identificado como lesão inicial. Foi também descrita a evolução das lesōes maculosas que, de turgidas e suculentas evoluem para a supuração em pontos localizados nas bordas da mácula, tendendo ao "esvaziamento".

Posteriormente, ainda em 1962, Baruzzi et alii publicaram mais nove casos de Blastornicose de Jorge Lôbo entre índios Caiabi do Parque do Xingu, salientando o polimorfismo das lesões, descrevendo nódulos, formações queloidiformes, placas infiltradas, pápulas e "áreas cicatriciais". Também na estatística de Baruzzi, as lesões que. loidiformes foram as menos freqüentes entre os doentes da nação Caiabi.

\section{MATERIAL E METóDos}

Os casos observados, um do sexo masculino, dois do sexo feminino, são índios Caiabi, da aldeia do Tatuí, próximo ao rio Arinos.

O diagnóstico foi baseado no exame clínico, biopsia e exame histopatológico realizado em S. Paulo pelo Dr. Décio Fleury da Silveira.

Os dados anamnésicos foram seriamente prejudicados pela dificuldade na comunicação: além da dificuldade resultante de um vocabulário tupi insuficiente, ainda existe a dificuldade em formular apropriadamente as perguntas a fim de obter a resposta correta.

A avaliação da idade foi feita à vista do desenvolvimento somático, número de filhos e outros dados de presunção.

\section{REsultados}

Caso 1 - Sexo masculino, idade provável 30-35 anos. Lesões masculosas em ambas as pernas, predominando na face externa e na perna esquerda onde atingem até o joelho. As lesões consistiam em máculas, de bordo irregular, eritematosas nos bordos e, nas lesões antigas, com coloração praticamente normal no centro da mácula. Bordos turgidos. Nos bordos, surgem com o tempo pequenas pústulas por onde escorre um líquido espesso, ligeiramente amarelado. Aparentemente, a eliminação daquele material é acompanhado de sensaçäo de alívio. Surgem em sucessão diversos pontos de supuração, havendo lesões com dois ou mais pontos dando saída àquela secreção. 
Após cada período de supuração, a lesão perde a sua turgescência em torno do ponto de saída do material, podendo no entanto ressurgir entumescimento, provocando a abertura de outro ponto de supuração. O processo repete-se em número indeterminado de vezes, havendo máculas em diferentes estágios evolutivos. Algumas máculas, que já supuraram repetidamente, não voltaram a entumescer, apresentando-se como áreas de pele atrófica, um tanto deprimida, com características de cicatriz residual.

Na perna, só se encontram lesões cicatriciais mas no terço inferior da coxa esquerda, já surge nova mácula, evidenciando a presença da blastomicose em atividade (fig. 1).

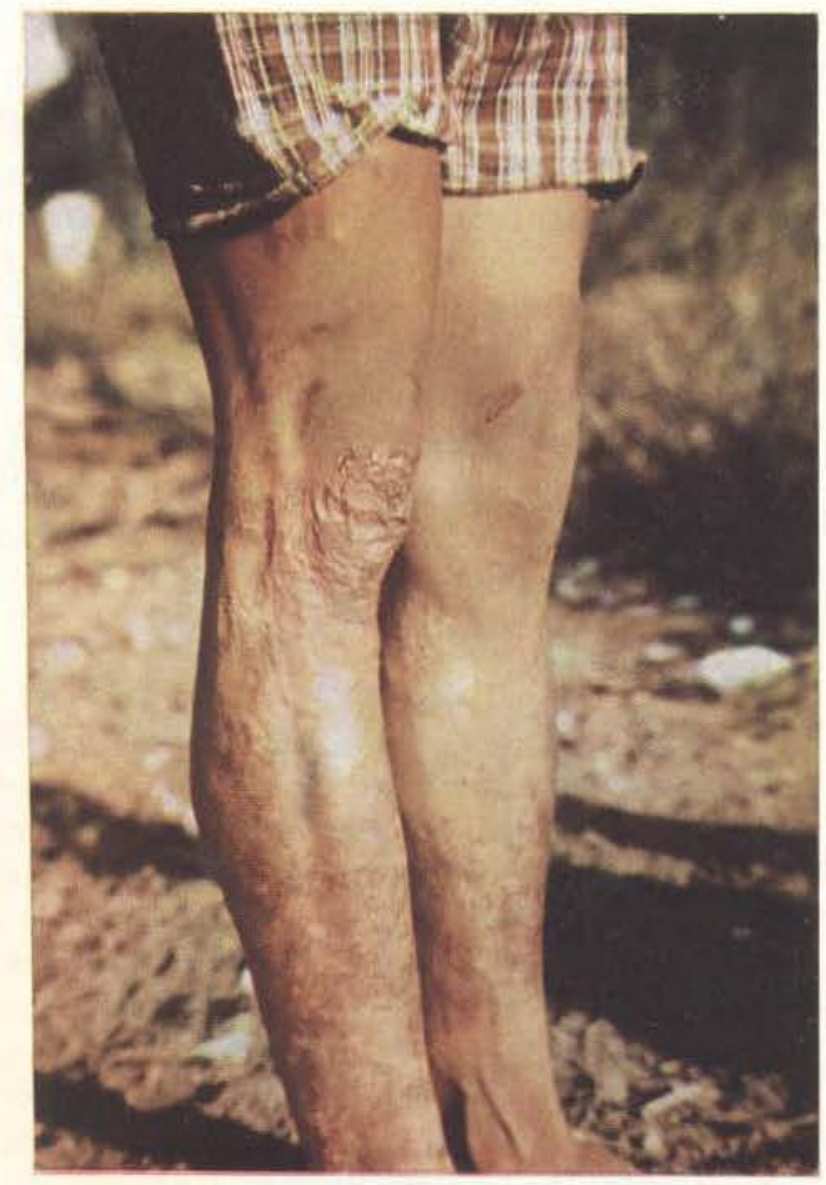

Fig. 1 - Blastomicose Quelodiforme de Jorge Lôbo em Indio Gaiabi. Regressão espontânea de lesão maculosa que ficou substituda por tecido cicatricial. Surgimento novas lesôes no terço inferior da face externa da coxa. (Foto P. Almeida Machado)
Caso 2 - Sexo feminino, idade provável 25-30 anos, originária da aldeia do Tatuí mas residindo presentemente nas vizinhanças de Dia. mantino, Mato Grosso.

Lesões cicatriciais nas pernas, predominando na face externa da perna direita. As lesōes evoluiram conforme descrito no caso 1 , apresentando-se hoje com o aspecto de cura aparente. No entanto, no braço, surge nova mácula. intervalo entre a cura aparente e o surgimento de nova mácula foi de aproximadamente um ano (fig. 2).

Caso 3 - Sexo feminino, idade provável 18-22 anos. Lesão única no seio esquerdo, evoluindo precisamente conforme descrito no caso 1. Todavia, neste caso, a secreção era freqüentemente sanguinolenta. A lesão terminou por se transformar em formação cicatricial inativa, e como tal permanecia havia dois anos quando foi examinada pela última vez. Por ocasião do último exame, não se descobriu qualquer outra lesão (fig. 3).

\section{DISCUSSÃo}

Nenhum dos trabalhos previamente publicados sobre a Blastomicose de jorge Lôbo aventou a possibilidade da regressão espontânea de lesōes, se bem que haja referências a "lesōes atróficas aparasitadas" (Pereira Filho, 1957), "máculas que sofreram "esvaziamento" (P. A. Machado, 1966) e "áreas cicatriciais" (Baruzzi et alii. 1967).

A evolução das máculas observadas pelo autor revela um processo cíclico de turgescência - supuração - turgescência, repetindo-se um número variável de vezes e, nos três casos descritos, tendendo ao esgotamento da secreção e regressão aparente da lesão.

Nos casos 1 e 2, a regressão não permite a hipótese de cura aparente pois já se registra a presença de nova mácula em atividade.

No caso 1 , existe coincidência de máculas em diferentes estágios, estando a moléstia em franca evolução. No caso 2 , houve um período de aproximadamente um ano sem lesão ativa. O caso foi considerado curado. A notícia da existência de um caso curado justificou uma ionga viagem que terminou numa certa de. cepção: depois de um ano de cura aparente. 
Fig, 2 - Blastomicose Quelodi. forme de Jorge Lôbo em Indio Calabi. Regressão espontânea $\mathrm{e}$ total lesão, ausência de novas lesōes após 2 anos de observação (Foto P. Almeida Machado)

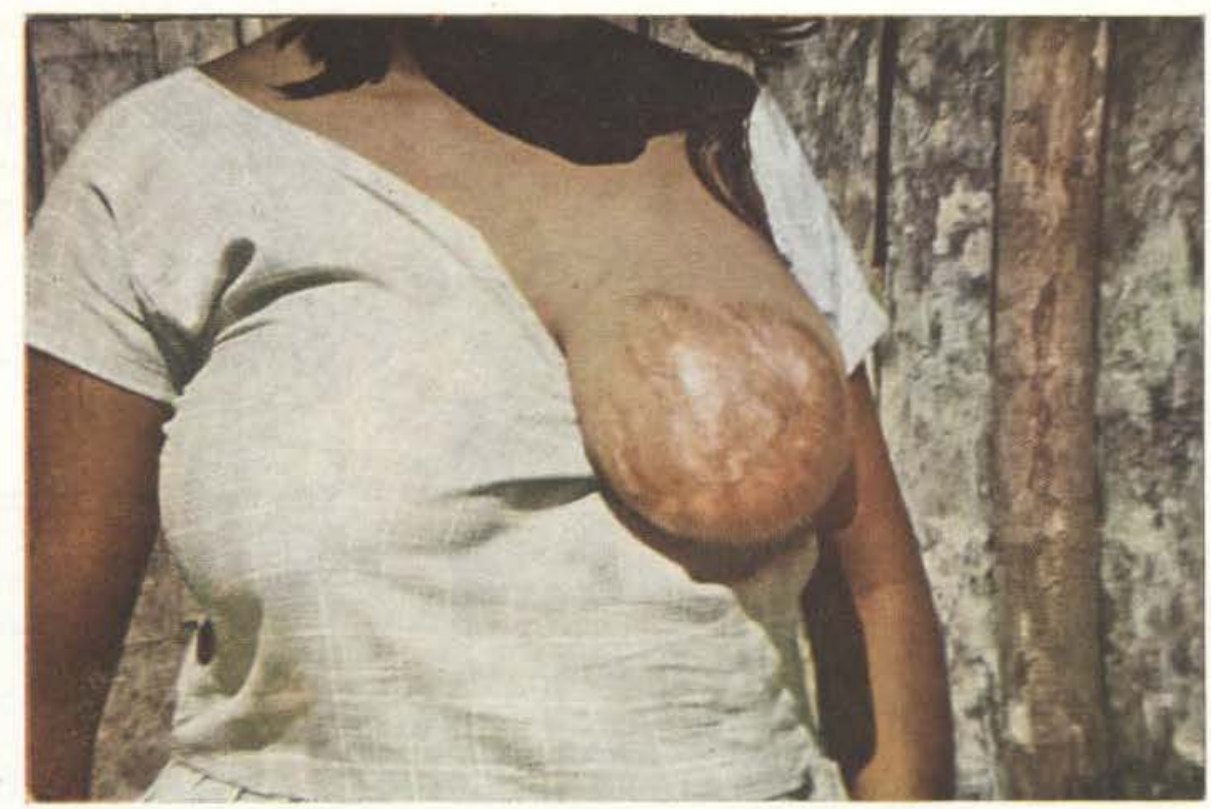

já surgia nova lesão à distância. Já no caso 3 , dois anos após a regressão completa da mácula. não surgiram outras lesões, estando o caso rotulado como "cura aparente há dois anos". Evidentemente ainda não há justificativa para se afirmar a cura espontânea da Blastomicose de Jorge Lôbo entre os índios Caiabi.

É, no entanto, notável a diferença entre a forma queloidiforme, de evolução lenta e progressiva, sem tendência à supuração, e a forma maculosa sofrendo modificações relativamente rápidas, com verdadeiras fases de acutização e evoluindo em alguns casos para a regressao total e definitiva da lesão, embora outra lesão viesse a surgir no mesmo indivíduo.

$\mathrm{O}$ fato merece registro uma vez que a integração da Amazônia irá abrindo oportunidades para o encontro de novos casos de blastomicoses de Jorge Lôbo e o conhecimento da peculiaridade da forma maculosa, evolutiva cíclica, poderá ser útil para o reconhecimento de casos que passariam despercebidos.

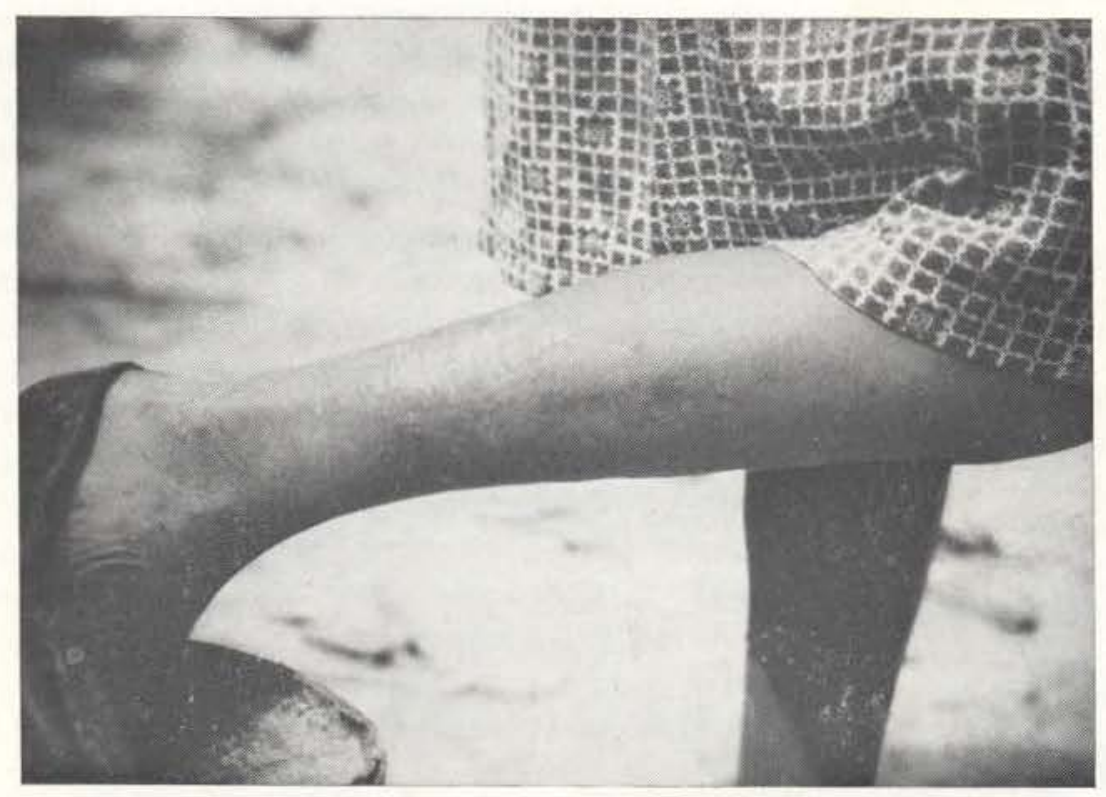

Fig. 3 - Blastomicose Quelodi. forme de Jorge Lôbo em Indio Caiabi, Regressão espontânea e total da lesão. Neste caso, havia no braço, surgimento de le. sões ativas

(Foto P. Almeida Machado) 


\section{CONCLUSÃo}

As lesões maculosas da Blastomicose de Jorge Lôbo, entre os índios Caiabi, apresentam tendência à evolução relativamente rápida, ocorrendo sucessivamente fases de entumescimento, supuração, esvaziamento e novo entumescimento recomeçando o cíclo. Em alguns casos, depois de repetido o cíclo em número variável de vezes ,a lesão se aplaina, não sofre novos entumescimentos e permanece como lesão cicatricial, curada. A ocorrência de novas lesões ativas, em área contíguas ou à distância, no mesmo paciente, revela que a regressão e cura de uma lesão não deve ser confundida com a cura do paciente.

\section{AGRADECIMENTOS}

A realização deste trabalho foi possível graças à colaboração do Dr. D. Fleury da Silveira, que realizou os exames histopatológicos indispensáveis ao diagnóstico, e aos Missionários Jesuítas Pe. Edgar Schmidt e Pe. João Dornstauden, que prestaram o imprescindivel apoio lo- gístico além de nos apresentar e recomendar ao pessoal da aldeia do Tatuí, tão próspera e tão, bem assistida por aqueles abnegados e humildes sábios.

\section{SUMMARY}

Macular lesions of Jorge Lobo's disease were found to be evolutive and spontaneous regression was observed in three patients among the Caiabi indians.

\section{BIBLIOGRAFIA CITADA}

BARUZZI, R. G. ET ALII

1967 - Ocorrência de Blastomicose queloidiana entre índios Caiabi. Rev. Inst. Med. Trop. S. Paulo, $9(3): 135-142$

Machado, P. A.

1966 - "Piraip, a chamada lepra dos Caiabi". In : Cong. Bras. Hig. XVI, Curitiba.

Peretra Filho, M. J

1957 - Os fungos da doença de Adolfo Lutz, da Doença de Jorge Lôbo e da blastomicose dos indior do Alto Xingu. Rev. Med. R, G. Sul, $14: 10-64$. 